\title{
The Impact of Prior-Knowledge on Farmers' Entrepreneurial Performance
}

\author{
PHEERAPHUTTHARANGKOON ${ }^{1}$, Huijun $\mathrm{Zhou}^{2}$, Hongdong Guo $^{3}$ \\ Center for Agriculture and Rural Development Zhejiang University, Hangzhou, China
}

\begin{abstract}
Entrepreneurial performance is an important indicator of the success of individual entrepreneurship. Successful entrepreneurial behavior is an important force to promote rural economic. So researches have been focus on the entrepreneurship for a long time. On the basis of survey data we have obtained from farmer entrepreneurs, this paper conducts an empirical analysis on "the impact of prior knowledge on farmers' performance". We conceptualize prior knowledge as having two dimensions: industry experience and functional experience. Results show that: The matching of farmers' functional experience and the richness of farmers' industry experience may have positive impact on the entrepreneurial performance.
\end{abstract}

Index Terms - Prior Knowledge, Entrepreneurial Behavior, Entrepreneurial Performance, Farmer Entrepreneurship

\section{Introduction}

When replying reporters' question, Premier Wen Jiabao said that, there are 0.9 billion farmers of the 1.3 billion Chinese and 30 million of the farmers have not escaped from poverty. The hysteresis of China's rural economy and the difficulty of continuous increase in farmer's incomes are thorny issues faced by China's Government. To solve these problems, the government announces a series of policies to promote farmers to start their own business. Nowadays, more and more farmers occur to the idea of starting their own business. As a result, hundreds of millions of farmers have become entrepreneurs. As farmer is a huge group in China, their contribution to the economy maybe significant. What kind of factors affect the performance of farmer entrepreneurs is an issue deserving deep study.

Entrepreneurial performance reflects the entrepreneurs' achievements and results and is an index for judging whether the business is successful. Entrepreneurial performance is the core issue in all the research on entrepreneurship (Shi Shude,2011)[4]. Researchers have studied factors affecting the entrepreneurial performance from various perspectives. Factors such as the external environment, the characteristics of entrepreneurs, strategic choice, organizational structure, resource integration capability, prior-knowledge, social capital and so on, have been proved to affect the entrepreneurial performance (Cai Li,2007[5]; Gao Xiangfei \& Wang Xiangmin, 2009[6]; Chen Hansong \& Zhu Xiaohong, 2012[7]; An Ning \& Wang Hongqi, 2011[8]; Xue Hongzhi, 2011[9]; Du Jianhua, 2009[10]). Among those factors, prior-knowledge as a peculiar quality of entrepreneurs is an important initial condition which can affect the entrepreneurial performance. So it catches many researchers' eyes (Xue Hongzhi, 2009 [11]; Tian Li \& Xue Hongzhi, 2009[12]; Yang Jun,2011[13]; An Ning \& Wang Hongqi, 2011[14]). Although researches in entrepreneurship have focused a lot on the influence of prior-knowledge to entrepreneurial performance, few researches studied how to influence. Existing researches about prior-knowledge just study part of the prior-knowledge which are always included in the study about human resource, personal characteristics or some basic information. They just investigate the quantity effects and have not done further researches about how to affect.

So this paper will study what the prior-knowledge contains and how can the entrepreneurial performance been influenced by different kind of prior-knowledge qualitatively and quantitatively. This paper is organized as follow, section 2 will give our research hypothesis basing on previous researches. Section 3 will introduce the source and measurement of our research data. Section 4 will do statistic analysis to get the results. Section 5 will discuss the results and give some policy suggestions.

\section{Theoretical Basis and Hypothesis}

Prior-knowledge includes the entrepreneurs' knowledge, skills, experience acquired from previous studying and working experience. For farmers, they are generally weak in cultural knowledge, so the prior-knowledge in this paper mainly means the knowledge getting not from formal education but from some other working and studying experiences which are main source and ability for them to start their own business. When investigate the entrepreneurs' prior-knowledge, the scholars mainly study the industrial experience and functional experience qualitatively and quantitatively (Xue Hongzhi, 2009[11]; Yang Jun, 2011[13]).

The relationship between entrepreneurs' prior-knowledge and performance has been a hot point studied by scholars and the research results are abundant. But the focuses on prior-knowledge are not all the same. When investigate the prior-knowledge under different research situation and from different perspective, scholars found the effects of prior-knowledge are different. Page West and Terry W. Noel(2009)[1] point out that the performance of a new-start enterprise depends on the strategy it adopts. And whether the strategy fits the enterprise depends on the entrepreneur's prior-knowledge which can decide entrepreneur's horizon. Research shows that if the entrepreneur has prior-experience about the new product, service and strategy, it will improve the performance of entrepreneurship remarkably. Aaron K. Chatterji (2009)[2] pointed out that in the high-tech industry, those who start their own business with previous working experience in a similar company can have better sense of 
the strategy and marketing so to get better performance than those who do not have such experiences. Xue Hongzhi (2009)[11] investigated the relationship between prior working experience and the performance of new enterprise and revealed that during the early stage, the entrepreneur's ability required is significantly different from large enterprise. Different functional working experience will have different impact on the initial performance. Diversified functional working experience will be conducive to the performance. And also their research shows that the matching level between working experience and the industry would not influence the performance. Tian Li \& Xue Zhihong (2009)[12] did the research from the perspective of entrepreneurial team and got the result that the more prior working experience, the better the initial performance. Because the prior-knowledge can help the entrepreneurs recognise and evaluate the opportunities and integrate the resource, and offer more information for organizing a new enterprise.

Although the existing research conclusions are not exactly the same, they all reveal the importance of prior-knowledge to entrepreneurial performance Functional experience make the entrepreneurs know better about the internal activities and coordination of their enterprises. So to get the experience and knowledge about setting relation network, employing, communicating with suppliers and clients to improve the performance. Industrial experience make the entrepreneurs master tacit knowledge about the knack for operation, demand trends and key profit point. So to promote their products to the market and improve the performance. The previous literatures are all about high-tech industries or new technology enterprises in which the entrepreneurs generally have a higher level of education. The prior-knowledge is so important to such well-educated entrepreneurs, so its influence on farmer entrepreneurs cannot be ignored. This paper proposes the following research hypothesis:

Hypothesis 1: The matching of Farmers' functional experience may have positive impact on the entrepreneurial performance. Hypothesis 2: The diversity of Farmers' functional experience may have positive impact on the entrepreneurial performance. Hypothesis 3: The relativity of Farmers' industry experience may have positive impact on the entrepreneurial performance. Hypothesis 4: The richness of Farmers' industry experience may have positive impact on the entrepreneurial performance.

\section{Data Collection and Variable Measurement}

According to the content and object of this research, we choose entrepreneurs household registered and self-employed in the agricultural sector or non-agricultural sector. We collected the data by questionnaires. The investigator team comprises of some graduate students from Zhejiang University majoring in Agricultural field and some are rural students form Agricultural Association in Zhejiang University. We extract 100 investigators from 22 provinces (cities). Each investigator extracts 6 farmer entrepreneurs randomly. To promise the validity of data, we trained the investigators in January 2012. At the conclusion of the study, we received 446 validly completed questionnaires from the 512 collected questionnaires. The questionnaire recovery rate and the effective rate of recovery of questionnaire were $85.33 \%$ and $74.33 \%$ respectively.

Zhang Yuli \& Wang Xiaowen(2011)[21] showed that industrial experience and functional experience are investigated fluently and deeply and such factors play prominent role in prior-knowledge. According to them we choose the above that two factors to do further research.

We measure the industry experience by investigating that after working, whether the farmers got related knowledge such as craft or skill, producing, marketing and clients $(\mathrm{Yes}=1, \mathrm{No}=0)$. The numerical index of industry experience is measured by the arithmetic sum of the value of those four kinds of knowledge. The attribute index of industry experience is measured by whether the entrepreneurial business is the same as the previous industry the entrepreneur engaged in $(\mathrm{Yes}=1, \mathrm{No}=0)$.

We measure the functional experience by asking the farmers whether they had performed some management job, sales work, technical work and production work. Those four express the management experience, sales experience, technical experience and producing experience (Yes=1,No=0). The numerical index of functional experience is measured by the arithmetic sum of the value of those four kinds of experience. The attribute index of functional experience is measured by whether the work task is the same as the previous one( $\mathrm{Yes}=1, \mathrm{No}=0)$.

Scholars attributed entrepreneurial performance to subject performance and objective performance. Objective performance measured by the objective data of enterprises. Subjective performance measured by non-accounting factors (Du Jianhua, 2009)[10]. Performance is a multi-dimensional concept, so there is almost no consensus about the appropriate performance variables in practical applications (Tian Li \& Xue Hongzhi, 2009[12]). When doing researches, researchers choose the variables as the case. Dess \& Elias(1998)[3] tried two ways to measure the performance of enterprises, after comparison and analysis, they proved that both subjective and objective judgments can reveal the objective performance.

The farmer subjects in our research are different in both the business and the scale of their enterprise. About $65.46 \%$ of them are self-employed and $17.16 \%$ of them are involved in partnership enterprises. On the one hand, the enterprise does not have standardized management so they do not have good financial record and they usually are not willing reveal the real financial information. On the other hand, the entrepreneurial business involves various industries in the primary, second and third industry. Such industries have their own growth and development characteristics, so the financial data are not comparable. By investigating the level of achievement of farmers' entrepreneurial goal, we judge the entrepreneurial performance on a personal level. 
According to the survey data, farmers' motivations to start their own business are improving living standard $(83.71 \%)$, achieving life goals $(36.88 \%)$, improving social status $(36.88 \%)$. This paper choose five grade self rating scale to measure three variable by asking three questions : 1 . The living standard is much better than before; 2 . The social status is much better than before; 3 . I am satisfied with my vocation. If the answer is totally disagree, disagree, neutral attitude, agree and totally agree. the valuation will respectively be 1, 2, 3, 4 and 5. And we take gender, age of entrepreneur, education level and the age of the entrepreneurial projects as controlled variable.

Table 1 shows the result of exploratory factor analysis of entrepreneurial performance. The reliability coefficient of 0.825 . The internal consistency reliability of measurement meets the requirement. The KMO test for sample adequacy is 0.654 , which means the number of samples is sufficient. Bartlett spherical test value is 483.233
$(\mathrm{P}<0.01)$, which means it suits for extracting common factors.

\section{Data Analysis and Results}

As farmer entrepreneurial performance are measured by continuous variable, scores of factors, so this paper employs hierarchical regression analysis to conduct the data. Before regression analysis, we standardize the variable, test and adjust the possible multicollinearity and related problems about heteroskedasticity and serial. Table 2 is the correlation coefficients matrix of variables. We can see that the matching of functional experience and the richness of industry experience have significant positive correlation with the entrepreneurial performance, the correlation coefficients were $0.110(\mathrm{P}<0.05), 0.103(\mathrm{P}<0.05)$.

Table 3 shows the regression results. We add controlled variable step by step in hierarchical regression Model 1, Model 2, Model 3, Model 4, Model 5 and Model 6.

Table 1. Exploratory factor analysis of entrepreneurial performance

\begin{tabular}{|c|c|c|c|c|c|}
\hline Variable & Minimum & Maximum & Mean & Factor loading & Reliability coefficient \\
\hline Living standard & 1 & 5 & 3.829 & 0.863 & \multirow{2}{*}{0.804} \\
\hline Social status & 1 & 5 & 3.718 & 0.770 & 0.905 \\
\hline Vocation Satisfaction & 1 & 5 & 3.630 & 2.158 \\
\hline The eigenvalue & \multicolumn{7}{|c|}{71.921} \\
\hline Cumulative variance(\%) & \multicolumn{7}{|c|}{} \\
\hline
\end{tabular}

The way we extract the common factors is principal component analysis methods.

Table 2. Correlation coefficients matrix of variables

\begin{tabular}{|c|c|c|c|c|c|c|c|c|c|}
\hline & Variables & 1 & 2 & 3 & 4 & 5 & 6 & 7 & 8 \\
\hline 1 & Entrepreneurial performance & 1 & & & & & & & \\
\hline 2 & Age & -.032 & 1 & & & & & & \\
\hline 3 & Years of Education & .061 & $-.367^{* *}$ & 1 & & & & & \\
\hline 4 & Age of entrepreneurial projects & $.100^{*}$ & .019 & $-.223^{* *}$ & 1 & & & & \\
\hline 5 & Matching of functional experience & $.110^{*}$ & .080 & .054 & -.054 & 1 & & & \\
\hline 6 & Diversity of functional experience & .060 & $.122^{*}$ & -.020 & -.021 & $.666^{* *}$ & 1 & & \\
\hline 7 & Relativity of Industry experience & -.002 & .004 & -.017 & -.027 & .031 & -.004 & 1 & \\
\hline 8 & Richness of industry experience & $.103^{*}$ & .025 & .044 & .038 & $.159^{* *}$ & $.257^{* *}$ & .000 & 1 \\
\hline
\end{tabular}

*Means $5 \%$ significantly correlated, **. Means $1 \%$ significantly correlated

Table 3. Hierarchical regression result

\begin{tabular}{|c|c|c|c|c|c|c|}
\hline \multirow{2}{*}{ Independent variable } & \multicolumn{9}{|c|}{ Dependent variable } \\
\cline { 2 - 7 } & Model 1 & Model 2 & Model 3 & Model 4 & Model 5 & Model 6 \\
\hline Intercept & -0.542 & -0.331 & -0.378 & -0.323 & -0.448 & -0.089 \\
\hline Age & 0.001 & -0.002 & -0.002 & -0.003 & -0.001 & -0.007 \\
\hline Years of Education & $0.031^{*}$ & 0.019 & 0.022 & 0.016 & $0.033^{*}$ & 0.013 \\
\hline Age of entrepreneurial projects & $0.035^{* *}$ & $0.039^{* * *}$ & $0.038^{* * *}$ & $0.037^{* *}$ & $0.035^{* *}$ & $0.035^{* *}$ \\
\hline Matching of functional experience & & $0.118^{* *}$ & & & & $0.11^{*}$ \\
\hline Diversity of functional experience & & & 0.071 & & & -0.025 \\
\hline Relativity of Industry experience & & & & -0.01 & & 0.004 \\
\hline Richness of industry experience & & & & & $0.098^{* *}$ & $0.092^{*}$ \\
\hline R2 & 0.018 & 0.031 & 0.023 & 0.016 & 0.033 & 0.039 \\
\hline F & $2.655^{* *}$ & $3.39 * * *$ & $2.417^{* *}$ & 1.532 & $3.349 * * *$ & $2.016^{* *}$ \\
\hline
\end{tabular}

$*, * *, * * *$, Means $10 \%, 5 \%$, and $1 \%$ significantly correlated respectively 
According to Table 2 and Model 2, we can see that the matching of functional experience has significant positive impact on farmer entrepreneurial performance $(\beta=0.118$, $P<0.05$ ). Hypothesis 1 is verified. However, model 3 shows the diversity of farmers' functional experience does not have significant impact on entrepreneurial performance, so hypothesis 2 is rejected. Model 4 rejects hypothesis 3. Model 5 show that the richness of functional experience has significant positive impact on farmer entrepreneurial performance $(\beta=0.098, \quad P<0.05$ ), hypothesis 4 is verified.

\section{Conclusion and Implication}

This paper deeply investigates the prior-working experience including functional experience and industry experience and proves that they have significant impact on farmers' entrepreneurial performance. First of all, we found that the more matching the functional experience with the entrepreneurial industry position, the better the entrepreneurial performance will be. According to the fieldwork, most farmer entrepreneurs choose individual or partnership entrepreneurial formats, themselves are the actual decision makers and managers. So the matching of functional experience is reflected in the experience of management. However, the experience in sales, technology work and production work appears less important. This result is totally different from previous studies. Secondly, richness of industry experience such as technical skills, product knowledge, marketing knowledge and client knowledge will promote the entrepreneurial performance. Because farmer entrepreneurs need industry common knowledge to improve the tacit knowledge about the related industry such as operation expertise, variation trend of demand and the key profit point. All of which can make them more sensitive and give them system thinking to handle the decision making task under uncertainty. But the relativity of the entrepreneurial industry and previous industry has no impact on the performance.

Basing on the above results, this paper gives two implications for farmers entrepreneurs. On the one hand, for those who plan to start their own business, the prior-working experience is important to build their own knowledge system and improve their ability. They should deliberately open their mind to accumulate industry knowledge, marketing information, client resources and so on. Meanwhile they should seize opportunity to take part in management practice and learn operation knowledge. On the other hand, for those who have began their business, they should use their prior-knowledge adequately to motivate the inner wisdom and external resources so to cover the shortage of education.

\section{References}

[1] Page West III and Terry W. Noel: The Impact of Knowledge Resources on New Venture Performance. J. Journal of Small Business Management, 2009(47): 1-22

[2] AARON K. CHATTERJI: Spawned with a Silver Spoon? Entrepreneurial Performance and Innovation in the Medical Device Industry. J. Strategic Management Journal,2009(30): 185-206

[3] Dees, J.G. \& Elias, J.: The challenges of combining social and commercial enterprise. J. Business Ethics Quarterly, 1988, 8(1): $165-178$

[4] Shi Shude, Zhang Wei, Gao Jian: Improving New Venture's Performance: An Entrepreneurial Team's Perspective. J. Journal of Industrial Engineering and Engineering Management, 2011, 25(4):44-51

[5] Cai Li, Ge Baoshan, Zhu Xiumei, Fei Yupeng, Liu Qing, Construction of entrepreneurship research framework based on resource view. J. China Industrial Economy,2007(11):96-103

[6] Gao Xiangfei, Wang Xiangmin, A new institutionalism framework: Institutional transformation, organizational structure and firm performance. J. Research of Institutional Economics, 2009(3): 127-145.

[7] Chen Hansong, Zhu Xiaohong, Research about new enterprise heterogeneous resources, resource acquisition and entrepreneurial performance-from the perspective of entrepreneurial opportunity. J. Review of Economy and Management. 2012(3):76-80.

[8] An Ning, Wang Hongqi. An Empirical Study Based on the perspective of initial conditions: Entrepreneurs' prior experience, learning mode and new technology enterprises' performance. J. Journal of Business Economics. 2011(9):34-42.

[9] Xue Zhihong. Entrepreneurial team the formal structure and the performance of new ventures, J. Journal of Management Science. 2011(1):1-9.

[10] Du Jianhua, Tian Xiaoming, Jiang qinfeng. Research based on the dynamic capabilities of the enterprise social capital and entrepreneurial performance. J., China Soft Science. 2009(2): 115-126.

[11] Xue Hongzhi, Wang Yinjun, Tian Li. Research on the relationship between prior-working experience and initial performance of new enterprises. Studies in Science of Science, 2009(6):896-903.

[12] Tian Li, Xue Hongzhi.An interaction effect model and its implication-entrepreneurial team's prior experience, commitment and new technology venture's initial performance. J.R\&D Management, 2009(4):2-9.

[13] Yang Jun, Xue Hongzhi, Niu Fang. An interaction effect model and implication-Prior experience, entrepreneurial opportunity and new technology enterprises' performance. J. Chinese Journal of Management. 2011(1):116-125.

[14] An Ning, Wang Hongqi. An Empirical Study Based on the perspective of initial conditions: Entrepreneurs' prior experience, learning mode and new technology enterprises' performance. J. Journal of Business Economics. 2011(9):34-42.

[15] Zhang Yuli, Wang Xiaowen, Empirical research of prior-experience, learning style and entrepreneurial ability. J. Journal of Management Science. 2011(3):1-12. 